\title{
Anaesthetic management of a case of atrial septal defect with mild pulmonary hypertension with bronchial asthma coming for emergency LSCS
}

\author{
Majula R ${ }^{1}$, Chaithra G.V. ${ }^{2}$, Gandhi ${ }^{3}$, Aastha ${ }^{4}$, Vinutha D. K. ${ }^{5}$ \\ ${ }^{1}$ Dr Manjula R, Associate Professor, ${ }^{2}$ Dr Chaithra G. V, Post Graduate Resident, ${ }^{3}$ Dr Amit Gandhi, Post Graduate \\ Resident, ${ }^{4}$ Dr Aasthaa, Post Graduate Resident, ${ }^{5}$ Dr Vinutha D. K, Post Graduate Resident, Department of \\ anaesthesiology, All are affiliated with Adichunchanagiri Institute of Medical Sciences, Balagangadharanatha Nagara, \\ Nagmangala Taluk, Mandya district, Karnataka, India.
}

Address for correspondence: Dr Chaithra G V, Post Graduate Resident, Department of anaesthesiology, Adichunchanagiri Institute of Medical Sciences, Balagangadharanatha Nagara, Nagmangala Taluk, Mandya district, Karnataka, India. Email: chaithragv24@gmail.com

\begin{abstract}
ASD one of the most common acyanotic congenital heart disease in women of child bearing age and pregnancy, it accounts for about $10 \%$ of all congenital heart disease. During pregnancy ASD is usually well tolerated. Bronchial asthma can complicate $1-7 \%$ of pregnancies. Uncontrolled asthma may produce serious maternal and fetal complications like PAH, fetal hypoxemia. These patients are considered to have high risk for anaesthesia due to increased perioperative cardiovascular and pulmonary complications. During anaesthesia our objectives are to avoid hypotension, hypoxemia, reversal of shunt and fluid overload.
\end{abstract}

Here we report the successful management of a parturient with ASD, mild PAH with bronchial asthma posted for emergency caesarean section, managed under sub-arachnoid block.

Key words: Atrial septal defect (ASD), Bronchial asthma, Pulmonary arterial hypertension (PAH), Lower segment caesarean section (LSCS).

\section{Introduction}

The prevalence of cardiac diseases during pregnancy is about $0.4-1.4 \%[1,2]$, with ASD being most common among these. ASD is a left to right type of cardiac shunt which may cause PAH [3] (pressure > 35mmhg). Mild to moderate ASD is usually well tolerated during pregnancy. These patients may be benefitted by supplemental oxygen given through face mask throughout the procedure, which may decrease the chances of them developing hypoxia caused by reversal of shunt due to elevation of pulmonary vascular resistance. Bronchial asthma is also commonly seen to complicate pregnancy [4]. Fetal oxygenation is affected more by maternal alkalosis than by hypoxemia, which can occur during uncontrolled asthma, thus asthma

Manuscript received $12^{\text {th }}$ May 2016

Reviewed: $25^{\text {th }}$ May 2016

Author Corrected: $10^{\text {th }}$ June 2016

Accepted for Publication $20^{\mathrm{th}}$ June 2016 should be well controlled.

The anaesthetic goals here are:

1. To prevent hypoxia, acidosis, hypercapnia and profound hypotension [5].

2. To prevent air embolism, by avoiding accidental injection of air intravenously.

3. To avoid the drugs which cause bronchospasam. Here we are reporting a case of pregnancy with ASD with mild PAH with Bronchial asthma, which was successfully managed with subarachnoid block.

\section{Case Summary}

A $22 \mathrm{yrs} 3^{\text {rd }}$ gravida parturient with previous two spontaneous abortions, presented to us at 37 weeks of 
pregnancy for emergency caesarean section in veiw of failure to progress and decreased fetal movements. She gave a history of palpitations and breathlessness (NYHA-II), since eighth month of gestation, swelling of legs since 1 month and history of bronchial asthma since 6 years for which she was on rotahaler (budesonide). Last episode was two weeks back, her exercise tolerance was good. No other significant positive history. On general physical examination bilateral pitting edema was noted, pulse rate was $86 \mathrm{~b} / \mathrm{min}$ regular good volume, RR was 20 cycles/min, $\mathrm{BP}$ was $130 / 80 \mathrm{mmhg}, \mathrm{spo}_{2}$ was $90-92 \%$ in room air. . On systemic examination, $\mathrm{B} / \mathrm{L}$ fine crepitations were heard in basal lung fields and a systolic murmur was heard in tricuspid area with loud second heart sound. Her airway examination revealed adequate neck extension, with mallampatti grade 3 , and adequate mouth opening. Her Echocardiography which was done in $8^{\text {th }}$ month of pregnancy revealed $20 \mathrm{~mm}$ ostium secundum ASD with grade one tricuspid regurgitation, with mild PAH (35mmh) dilated right atrium and right ventricle and ejection fraction of $70 \%$, She was advised to get transesophageal echo after delivery. The ECG showed sinus rhythm with right axis deviation. Patient was nil by mouth since 4 hours.

Procedure was explained to patient and consent was taken. Our plan of anesthesia was in favour of subarachnoid block,over general anaesthesia., As it minimizes the exposure of fetus to adverse effects of general anaesthetics, avoid medling of maternal airway, and also patient had stable vitals. Prophylaxis was given with IV 50mg Ranitidine and 4mg Ondensetron. Budecortisone nebulisation was given. Patient was shifted to OT and Standard monitors connected. IV Ringer lactate was started with $18 \mathrm{G}$ canula, IV $2 \mathrm{gm}$ Ampicillin was given. Under aseptic precautions subarachnoid block was given with Inj-Bupivacaine $0.5 \%$ heavy $1.4 \mathrm{ml}+$ Inj-fentanyl $0.4 \mathrm{ml}$. Maternal oxygenation was ensured with $5 \mathrm{~L}$ of $\mathrm{O}_{2}$ through facemask through out the procedure. Adequate level of anaesthesia was obtained till T6. All vital parameters were monitored intraoperatively. Patient was given IV Oxytocine 10 units in a drip, after the baby of birth weight $2.8 \mathrm{kgs}$ was delivered. Patient was heamodynamically stable throughout the procedure and postoperative period was uneventful.

\section{Discussion}

ASD is the most common congenital lesion of child bearing age in women, which is usually well tolerated in pregnancy, but there is increased risk of LVF [6,7]. Anatomically ASD classified into Sinus venosus, ostium primum and ostium secundum types out of which secundum (formed in the region of fossa ovalis) type accounts for about $70 \%$ of cases. The size of the defect and the relative compliance of ventricles determine the direction and magnitude of shunt. Small defect $<0.5 \mathrm{~cm}$ has no heamodynamic sequelae, but in a shunt of about $2 \mathrm{~cm}$ diameter, it is likely that the left atrial blood is shunted to right atrium along the pressure gradient, resulting in increased pulmonary blood flow. When the pulmonary blood flow is 1.5 times the systemic blood flow it leads to right ventricular dysfunction and irreversible PAH [8, 9]. ASD in pregnancy is of special concern because pulmonary hypertension in pregnant women carries high mortality and death regardless of severity of the disease. Following delivery, fluid from interstitial space is suddenly shifted to maternal circulation, increasing preload significantly and further increasing PAH [9]. This results in highest risk of PAH during first 10 days of post-partum period. Bronchial asthma affects $4-8 \%$ of all pregnant women and it tends to worsen during $6^{\text {th }}$ to $8^{\text {th }}$ month of pregnancy. Exposure to fetal antigens leading to alterations in immune functions may predispose some pregnant asthmatic women to worsening of asthma. In such cases inhaled corticosteroids like budesonide are recommended [10]. 15-methyl PGF2- alpha and methylergonovine which cause bronchospasm, are better avoided intraoperatively. In this patient goal of management was to avoid increase in pulmonary vascular resiastance, the maintainence of systemic vascular resistance, avoid decrease in venous return [11,12] and avoid infective endocarditis by giving prophylactic antibiotics when cardiac valvular abnormality is present along with ASD. General anaesthesia for LSCS has the disadvantages of maternal myocardial depression, neonatal depression, sudden cardiovascular collapse and airway manipulation. If preload and after load are maintained, regional blocks can be given.

Considering all the above factors we preferred spinal anaesthesia and the case was managed successfully without affecting heamodynamic stability.

\section{Conclusion}

Successful outcome was experienced by the use of subarachnoid block in this case. However no definite conclusion can be drawn from a single case and one should tailor the anaesthesia technique to avoid increase 
in PVR, decrease in SVR, hypotension and hypoxia with meticulous intraoperative and postoperative monitoring. It is demonstrated that in selected cases, caesarean section can be performed under subarachnoid block in patient with ASD and bronchial asthma.

Funding: Nil, Conflict of interest: None initiated. Permission from IRB: Yes

\section{References}

1. David H Chestnut. Principles and practice of obstetric anaesthesia Elsevier Mosby-Philadelphia, Pennsylvania 2004;3:707-33.

2. Kuczhowski KM. Labour analgesia for parturient with cardiac disease - what does an obstetrician need to know? Acta Obstet Gynecol Scand 2004 Mar;83 (3) : 223-33.

3. Smedstad KG, Cramb R, Morrison DH. Pulmonary hypertension and pregnancy: a series of eight cases. Can J. Anaesth 1994 Jun; 41(6):502-12.

4. NAEPP Expert Panel Report. Managing asthma during pregnancy: recommendations for pharmacological treatment- update 2004. J Allergy Clin Immunol 2005 Jan; 115(1): 34-46.

5. Atanassoff P, Alon E, Schmid ER, Pasch TH. Epidural anaesthesia for caesarean section in a patient with severe pulmonary hypertension. Acta Anaesth Scand $1989 ; 33: 75-7$.
6. Sullivan JM, Ramanathan KB. Management of medical problems in pregnancy-severe cardiac disease. N Engl J Med. 1985 Aug 1;313(5):304-9.

7. Harnett M, Mushlin PS, Camann WR. Cardiovascular disease. In: Chestnut DH, ed. Obstetric anesthesia: principles and practice, 3rd ed. Philadelphia: Elsevier Science, Mosby; 2004;707-33

8. Lewis J. Rubin. Primary Pulmonary Hypertension. N Engl J Med. 1997 Jan; 336(2): 111-17.

9. Khan MJ, Bhatt SB, Krye JJ. Anesthetic consideration for parturient with Primary Pulmonary Hypertension : review of literature and clinical presentation. International J of Obst. Anesthesia 1996; 5 (1): 36-42.

10. Bracken MB, Triche EW, Belanger K, et al. Asthma symptoms, severity, and drug therapy: a prospective study of effects on 2205 pregnancies. Obstet Gynecol. 2003 Oct; 102(4): 739-52.

11. Johnson MD, Saltzman DH. Cardiac disease. In: Datta S (Ed.). Anesthetic and Obstetric Management of High-Risk Pregnancy. St. Louis: Mosby - Year Book, Inc, 1991; 237: 245-51.

12. Roessler P, Lamberet TF. Anaesthesia for caesarean section in the presence of primary pulmonary hypertension. Anaesth Intensive care. 1986 Aug; 14(3): 317-20.

\section{How to cite this article?}

Majula R, Chaithra G.V., Gandhi A, Aastha, Vinutha D. K. Anaesthetic management of a case of atrial septal defect with mild pulmonary hypertension with bronchial asthma coming for emergency LSCS. Int J Med Res Rev 2016;4 (6):10491051.doi: 10.17511/ijmrr.2016.i06.32. 